This is a self-archived version of an original article. This version may differ from the original in pagination and typographic details.

Author(s): Isomottonen, Ville; Hamalainen, Ville; Clark, Jennifer; Lappalainen, Vesa

Title: Exploring students' identity development from the perspective of study difficulties

Year: 2020

Version: Accepted version (Final draft)

Copyright: @ IEEE, 2020

Rights: In Copyright

Rights url: http://rightsstatements.org/page/InC/1.0/?language=en

Please cite the original version:

Isomottonen, V., Hamalainen, V., Clark, J., \& Lappalainen, V. (2020). Exploring students' identity development from the perspective of study difficulties. In FIE 2020 : Proceedings of the 50th IEEE Frontiers in Education Conference. IEEE. Conference proceedings : Frontiers in Education Conference. https://doi.org/10.1109/FIE44824.2020.9273923 


\title{
Exploring students' identity development from the perspective of study difficulties
}

\author{
Ville Isomöttönen*, Ville Hämäläinen*, Jennifer Clark †', Vesa Lappalainen* \\ *Faculty of Information Technology \\ University of Jyväskylä \\ Jyväskylä, Finland \\ Email: ville.isomottonen@jyu.fi, vilbohamalainen@gmail.com, vesa.t.lappalainen@jyu.fi \\ $\dagger$ Norm Asbjornson College of Engineering \\ Montana State University \\ Bozeman, MT, USA \\ Email: jennifer.clark6@montana.edu
}

\begin{abstract}
This work-in-progress paper in research category reports preliminary findings on how students taking introductory computing courses develop identity from the perspective of study difficulties. The motivation was that students identified lack of meaning and prospects (cf. identity) as a study difficulty in a previous qualitative study. The present study further explores this finding by issuing both an identity development and a selfefficacy scale to a larger first-year student cohort. The aim is to characterize the study cohort by the aspects included in the identity development scale, and thereby increase understandings of students' challenges. Moreover, a correlation analysis between identity development and self-efficacy was performed to explore if, for instance, low self-efficacy related to yet a loose identity choice. We also examined the effect of age. Main observations included that many students showed ruminative exploration of identity, which was negatively associated with self-efficacy. Altogether, a rather high number of negative and neutral responses with respect to the identity choice was observed. An initial look at self-efficacy distributions suggests that students related to challenge positively, while a large number of neutral answers were found with respect to the dimension of Effort. This might be indicative of uncertainty about doing the work. Regarding the effect of age, younger students were observed to worry more about the future compared to older students.
\end{abstract}

\section{INTRODUCTION}

This study explores students' identity development from the perspective of study difficulties. Study difficulties are described in the studies on students' transitions to the university, which have focused on aspects such as self-regulation (e.g., [1]), learning-to-learn aspect (e.g., [2]), academic level of study (e.g., [3]), and self-efficacy (e.g., [4]). Another line of literature that describes study difficulties is dropping out from higher education. This research has documented factors that influence students' considerations between staying or leaving; see [5]-[8]. The present study can be seen to relate to the Tinto's recent theorization [9] on retention from the perspective of students' study motivation. In his framework, both self-efficacy and how students perceive curriculum were emphasized as antecedents of study motivation.

Our previous study [10] illustrated how CS students experience self-efficacy challenges and lack of prospects and meaning (cf. perceptions of curriculum in Tinto's work) during their first year of study. The present goal is to further understand this lack of meaning together with the self-efficacy challenge: an identity development questionnaire and a selfefficacy questionnaire were issued to students who could be reached at the end of a CS1 course through an LMS. The former questionnaire incorporates several dimensions of identity development and examines if the respondent identifies a meaningful direction for life, and hence if some form of identity is developing. The inclusion of the latter questionnaire allows correlation analyses between student-reported self-efficacy and the dimensions of identity development. A total of 197 students answered to the questionnaires in full, which is roughly half of the population that was reached out. Descriptive statistics are reported and discussion provided on the prevalence of different dimensions of identity development and relatedly on potential 'lack of meaning' indications among study population. How self-efficacy, age, and study major influence student-reported identity is also examined.

\section{BACKGROUND}

\section{A. Related work}

Two references contextualize the present research. The first is Tinto's theorization [9] that conceptualized students' persistence in relation to motivation. Drawing on many scholars, Tinto emphasized that trying to understand persistence from the students' perspective necessarily indicates looking at students' motivation to study. Experiences that students gain in their institutions were considered to affect this motivation. Tinto identified three important constituents that influence the motivation: self-efficacy, belongingness, and perceptions of curriculum. The first is a situational belief regarding ability to succeed under a given circumstance [11]. Tinto put that self-efficacy provides foundation for persistence, and summarized that even students with sufficient academic ability are troubled with low self-efficacy. Belongingness denotes that students should be able to experience themselves as part of a community (e.g., faculty). Experiences of belongingness were considered to be influenced by institutional climate and 


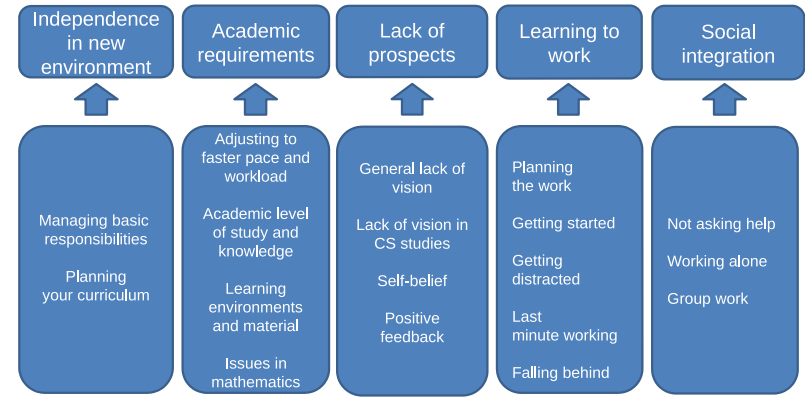

Fig. 1. Previous findings [10]

daily interactions therein. The perceptions of curriculum refer to the experienced quality and relevance of curricula, and was considered to be influenced by matters such as teaching methods, learning style preferences, and values.

The other reference is Turner's [12] study on the development HE students' self-belief for employability. She argued that students should be able to develop through

belief that their ability can be developed and improved to allow for attainment of their goals; belief in their ability to plan and execute action to achieve their goals; belief that the environment/context will allow for goal attainment. (p. 597)

Turner thus emphasized context as an important consideration for increasing students' perceived ability. The implication she offered was that contexts should foster mastery experiences and provide encouraging messages about ability. Therefore, Turner's work asks faculties to look at if necessary and what kinds of support and feedback mechanisms are implemented, and aligns with the Tinto's considerations above. Moreover, self-belief conceptualized in connection to employability aligns well with what a previous qualitative raised as students' study difficulties (see next section).

\section{B. Background locally}

A previous qualitative study mapped student-experienced difficulties after they had studied (been officially present) at least one academic year [10]. The study was based on CS students' self-reports collected at the beginning of small-group workshops focusing on study difficulties. Figure 1 summarizes the categories that were extracted from the students' writings. Many of these can be found in the literature in a way or another. However, the aspect perhaps receiving less attention in the corridors of academia, as compared to self-regulation (cf. the challenge with independence in the Figure) and increasing academic requirements, was considered to be the "Lack of prospects," under which the students' considerations of feedback were also situated; see Figure 1. This category indicates that students do not consider studying meaningful and/or do not envisage where their CS education leads to. Lack of future prospects were stated both generally and related to studying CS-see Figure 2. This "Lack of prospects" perspective (or lack of meaning) appeared to relate to how Tinto outlined students' view of curriculum as a factor
General lack of vision

S19: When I get the blues, it's really hard to start studying on my own time. I feel anxious about the fact that there is not going to be anything meaningful during the day, and I postpone studying while trying to find something meaningful.

S7: Perhaps I associate studying with boring and numbing exercises, and my negative S7: Perhaps I associate studying with boring and numbing exercises,
emotions are holding back my studies. I should learn to enjoy studying.

Lack of vision in CS studies

S3: Perhaps I have not really found the courses to be interesting enough, so that I would bother doing the extra work for a one grade improvement.

S17: Lack of motivation makes me ponder if I should use my time better, for example, applying for a job or learning interesting things on my own, instead of "wasting" time on courses that take a lot of time but feel like they don't benefit me at all.

Self-belief

S12: On the other hand, I would like more practicality in my studies. However, I feel that my skills are at so low level that for example getting an internship feels impossible. The practical work in the programming courses have mainly made me uncertain of being able to build programs that actually work.

Positive feedback

S12: There has been success also but sometimes it feels like success is overshadowed by challenges.

S10: The best thing in studying is the feeling of succeeding. The feeling after you have practiced a lot, getting a good grade, and can apply the things you've learned. When I get this feeling, I realize again why I need to study, and how much benefit studying has on my future. This feeling makes me study.

Fig. 2. Illustrations of "Lack of prospects" from [10]

underlying study motivation (see above) and how both Tinto and Turner emphasized belief in self.

\section{Scales for identity development and self-efficacy}

To continue the research (Section II-B), a scale reflecting the Lack of prospects-perspective was screened. Dimensions of Identity Development Scale (DIDS) [13] was deemed applicable. The Luycks' et al. [13] version of the scale consists of five dimensions describing varying conditions of identity development: commitment making $(C M)$; exploration in breadth $(E B)$; ruminative exploration (RE); identification with commitment (IC); exploration in depth (ED). Table I displays the scale items according to these dimensions. Luyckx et al. [13] explained that this scale originates in Marcia's [14] efforts to operationalize Erickson's [15] work on identity. Marcia's model was comprised of four identity status types. Luycks et al. divided both 'commitment' and 'exploration' -aspects found in the Marcia's and others' previous research into two more fine-grained aspects of commitment and exploration [16]. 'Ruminative exploration' was introduced later, representing a maladaptive exploratory process in identity exploration [13]. Altogether, the scale explains identity exploration through openness and curiosity, on the one hand, and anxiety and depression, on the other [13]. The scale has been shown to produce consistent results in a variety of settings, and scholars have also used a six-dimensional version with the same 25 questions [17]. We applied the five-dimensional scale. ${ }^{1}$ See more of the theoretical background in [13] and [17].

Morsunbul and colleagues tried the scale in a Turkish settings, finding identity dimensions as critical factors in behavior [18] [19]. Mannerstrom et al. [17] validated the instrument and assessed the patterns of identity among Finnish youth with a wide variety of backgrounds, and recommended use of DIDS in longitudinal research in varying contexts. DIDS was also found adaptable for use in Circumplex of Identity Formation Modes (CIMF), a scale seeking to synthesize the

\footnotetext{
${ }^{1}$ A Finnish translation was received from Rasmus Mannerström; see his dissertation at http://urn.fi/URN:ISBN:978-951-39-7701-6.
} 
TABLE I

Items of Dimensions of IDENTITy DeVelopment SCALE [13]

\begin{tabular}{|c|c|}
\hline $\mathrm{CM}$ & $\begin{array}{l}\text { I have decided on the direction I am going to follow in my life. } \\
\text { I have plans for what I am going to do in the future. } \\
\text { I know which direction I am going to follow in my life. } \\
\text { I have an image about what I am going to do in the future } \\
\text { I have made a choice on what I am going to do with my life. }\end{array}$ \\
\hline EB & $\begin{array}{l}\text { I think actively about different directions I might take in my life. } \\
\text { I think about different things I might do in the future. } \\
\text { I am considering a number of different lifestyles that might suit me. } \\
\text { I think about different goals that I might pursue. } \\
\text { I am thinking about different lifestyles that might be good for me. }\end{array}$ \\
\hline $\mathrm{RE}$ & $\begin{array}{l}\text { I am doubtful about what I really want to achieve in life. } \\
\text { I worry about what I want to do with my future. } \\
\text { I keep looking for the direction I want to take in my life. } \\
\text { I keep wondering which direction my life has to take. } \\
\text { It is hard for me to stop thinking about the direction I want to follow in my life. }\end{array}$ \\
\hline IC & $\begin{array}{l}\text { My plans for the future match with my true interests and values. } \\
\text { My future plans give me self-confidence. } \\
\text { Because of my future plans, I feel certain about myself. } \\
\text { I sense that the direction I want to take in my life will really suit me. } \\
\text { I am sure that my plans for the future are the right ones for me. }\end{array}$ \\
\hline ED & $\begin{array}{l}\text { I think about the future plans I already made. } \\
\text { I talk with other people about my plans for the future. } \\
\text { I think about whether the aims I already have for life really suit me. } \\
\text { I try to find out what other people think about the specific direction I decided to take in my life. } \\
\text { I think about whether my future plans match with what I really want. }\end{array}$ \\
\hline
\end{tabular}

multiple influences on identity formation for the purpose of conceptualizing how this dynamic phenomenon occurs [20]. Tools that measure identity related to a subject or setting are not uncommon. Capobianco et al. [21] [22] developed Engineering Identity Development Scale (EIDS) to study the dynamic nature of professional engineering identity development in college-age and younger students. To assess identity development from the perspective of study difficulties in CS context, DIDS was determined to be an appropriate scale.

General self-efficacy scale by Sherer et al. [23] was used. The scale stems from Bandura's [24, p. 193] theorization of self-efficacy expectations. An efficacy expectation refers to a belief that one is able to carry out the behavior needed to produce the outcomes [24, p. 193]. Such expectations regulate the degree of effort and persistence when obstacles and aversive experiences are encountered [24, p. 194]. The dimensions of the scale are: willingness to initiate behavior (INI), willingness to expend effort in completing the behavior (EF), and persistence in the face of adversity (PER) [23].

\section{STUDY}

The study explores first-year students' identity development, and if self-efficacy, age, or study major plays an important role in it. Students who could be reached through an LMS of the on-going CS1 course were asked to participate in research. The request was repeated at the beginning of CS2 course; these two courses follow one another. A total of N=197 answers were used in analyses after removing a few dozens of incomplete answers. The two scales used were DIDS and General selfefficacy scale discussed above. The limitation of this study is that it offers only preliminary descriptive statistics by which we intend to make conclusions about research setting and use of the selected scales. Inner validity of these inventories has been tested in previous research and is not addressed here. Moreover, the six-dimension version of the scale is left for future work. This refinement concerns dividing "Exploration in depth" dimension into two more fine-grained perspectives,
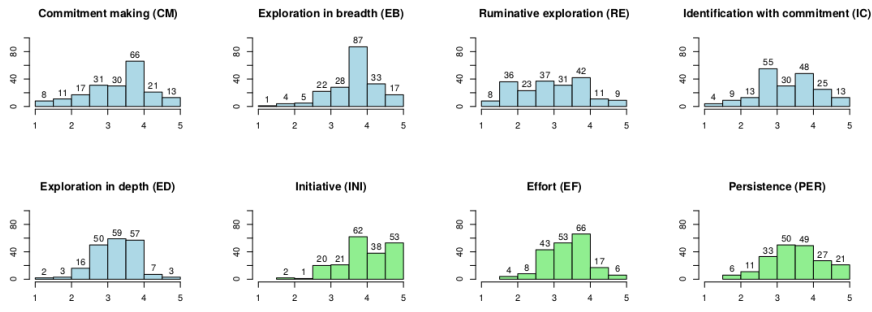

Fig. 3. Distributions of dimensions of the DIDS (blue) and General selfefficacy scale (green). A detailed view in which single student's average score at a summary variable (dimension) level can be and is here shown also between Likert scale values.

which take into account a positive reflective and negative reconsideration -aspects with commitment [17].

\section{RESULTS}

The analysis was conducted using $\mathrm{R}$ with Stargazer [25] and Hmisc [26] packages. The data consists of eight dimensions from the scales used. To begin with, Figure 3 displays distributions for these dimensions. Figure 4 shows distributions in a stacked bar chart. Regarding commitment making (CM), $51 \%$ of the population agreed to have a direction identified for life (e.g., has plans for the future). On the other hand, 18 $\%$ disagreed and $31 \%$ provided a neutral opinion, the latter of which, we argue, is noteworthy in the present context. Exploration in breadth (EB) seems to be clearly populated in the positive side, with $70 \%$ of the students pondering on the direction of their lives. Students' answers to Ruminative exploration (RE), indicating a worry of future, showed a scattered distribution. However, a considerably high number of students agreed to worry about their future $(31 \%)$, or provided a neutral answer in this respect (35\%). The largest number of neutral answers was found with the respect of Exploration in depth (ED). This may be indicative of students at the stage of taking introductory programming courses are not yet deeply considering their future plans. An initial look at selfefficacy distributions suggests that students relate to challenge positively. However, a large number of neutral answers are found with respect to the dimension of Effort (EF), which might be indicative of uncertainty about doing the work.

The correlations between the dimensions of the two scales are displayed as a Spearman's correlation matrix in Table II. Commitment making $(\mathrm{CM})$ had a significant negative correlation with Ruminative exploration (RE) $(\mathrm{r}=-.66, \mathrm{p}<.0001)$. Strong association was also observed with Identification with Commitment (IC) $(\mathrm{r}=.82, \mathrm{p}<.0001)$. Commitment making (CM) had also strong correlations with all self-efficacy factors: Initiative (INI) $(r=.36, \mathrm{p}<.0001)$, Effort $(\mathrm{EF})(\mathrm{r}=.46$, $\mathrm{p}<.0001)$ and Persistence (PER) $(\mathrm{r}=.44, \mathrm{p}<0.0001)$. Ruminative exploration (RE) had a negative correlation with all self-efficacy factors: Initiative (INI) $(r=-.38, p<0.0001)$, Effort (EF) $(r=.-046 \mathrm{p}<0.0001)$ and Persistence (PER) $(r=-$ $.52, \mathrm{p}<.0001)$. That is, worrying about future was associated with self-efficacy challenge. An interesting observation was that Ruminative exploration (RE) and Exploration in breadth 
TABLE II

CORRELATIONS BETWEEN THE DIMENSIONS OF THE TWO SCALES. $(* * * *=\mathrm{P}<.0001)$

\begin{tabular}{|c|c|c|c|c|c|c|c|}
\hline & $\mathrm{CM}$ & EB & $\mathrm{RE}$ & $\mathrm{IC}$ & ED & INI & $\mathrm{EF}$ \\
\hline Commitment Making (CM) & & & & & & & \\
\hline Exploration in Breadth (EB) & -0.08 & & & & & & \\
\hline Ruminative Exploration (RE) & $-0.64 * * * *$ & $0.45 * * * *$ & & & & & \\
\hline Identification with Commitment (IC) & $0.82 * * * *$ & -0.13 & $-0.66 * * * *$ & & & & \\
\hline Exploration in Depth (ED) & 0.06 & $0.52 * * * *$ & $0.36 * * * *$ & -0.03 & & & \\
\hline Initiative (INI) & $0.36 * * * *$ & -0.05 & $-0.38 * * * *$ & $0.42 * * * *$ & $-0.15^{*}$ & $0.57 * * * *$ & \\
\hline Effort (EF) & $0.46^{* * * * *}$ & -0.09 & $-0.46 * * * *$ & $0.54 * * * *$ & -0.13 & & \\
\hline Persistence (PER) & $0.44 * * * *$ & -0.12 & $-0.52 * * * *$ & $0.51 * * * *$ & -0.10 & $0.53 * * * *$ & $0.56 * * * *$ \\
\hline
\end{tabular}

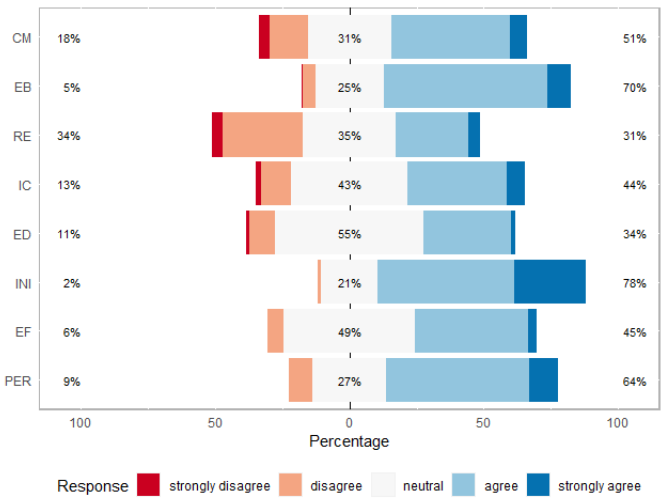

Fig. 4. Divergent Bar Plot presentation of the dimensions. The percentage on the left-hand side is sum of the strongly disagree and disagree answers, while the percentage on the right-hand side is a sum of the agree and strongly agree answers.

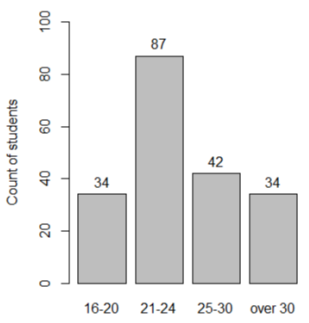

Fig. 5. Age distributions

(EB) nevertheless correlated strongly $(\mathrm{r}=.45, \mathrm{p}<.0001)$. All self-efficacy factors correlated with each other, an aspect that is of little interest in the current study setting.

Kruskal-Wallis Test was used to explore differences between age (see Figure 5) and the dimensions of DIDS and General self-efficacy scale. A significant correlation was found between age and commitment making $(\mathrm{CM})$ (chi-squared $=12.646, \mathrm{df}$ $=3, \mathrm{p}=.005469)$, and between age and Identification with commitment (IC) (chi-squared $=11.084, \mathrm{df}=3, \mathrm{p}=.01128$ ) older students appeared to be more aware of their plans. Moreover, a close to significant correlation was observed between age and Ruminative exploration (RE) (chi-squared = $7.4882, \mathrm{df}=3, \mathrm{p}=.05786$ ), which provides a faint indication of younger students being more prone to worry about the future. Regarding the study major, we observed much less nonempty answers $(\mathrm{N}=125)$ compared to the other questionnaire items $(N=197)$, and this goal was left for future work.

\section{DISCUSSION}

This study described a student cohort with respect to identity development and self-efficacy. The research was underpinned by a qualitative study from the same context, and the goal was to extend understandings of student cohorts with a different approach. "Lack of prospects" was reported by the students as a challenge in the previous qualitative study, and the present work provides indications and hypotheses that sit well in this category. For instance, we would point here the rather high number of answers that indicated a worry of future or a neutral response with respect of the dimension Ruminative exploration. Correlation analyses indicated a significant correlation between Exploration in Breadth (students pondering on their life direction) and Ruminative exploration (students worrying about their life direction), but yet that those pondering on their life direction (EB) did not identify with selfefficacy challenges. On the other hand, Ruminative exploration showed negative correlations with self-efficacy factors. These observation refine the previous qualitative study.

The high number of students either being concerned about their future or speculating about their choices reflects Tinto's [27] attention to both how a curriculum shows to beginner students and how their self-efficacy is addressed. The question that emerges is how a typical HE curriculum (as is the case here) consisting of the multitude of small courses and topics can support students' identification with a life directionwithout explicit attention given to it. Competence-based curricula emphasizing well-packaged learning items for particular skills at the cost of a thorough theoretical focus have been criticized [28]. Relatedly, when discussing the meaning of HE education studies, some intermediate CS students from the present context reported that university studies tend to be cursory reviews of the multitude of topics [29]. On these grounds, we argue that the meaning of curriculum and its ingredients should be constantly made explicit and discussed in classrooms. This refers to holistic pedagogic approaches, such as learning communities, which seem to have empirical support [30], but to our knowledge are not being comprehensively implemented in computing curricula. Research-wise, the present study is a starting point to do further diagnosis of the identity development and meaning experienced by students. 


\section{REFERENCES}

[1] A. Lizzio and K. Wilson, "Early intervention to support the academic recovery of first-year students at risk of non-continuation," Innovations in Education and Teaching International, vol. 50, no. 2, pp. 109-120, 2013.

[2] U. Wingate, "A framework for transition: Supporting 'learning to learn' in higher education," Higher Education Quarterly, vol. 61, no. 3, pp. 391-405, 2007.

[3] M. Leese, "Bridging the gap: Supporting student transitions into higher education," Journal of Further and Higher Education, vol. 34, no. 2, pp. 239-251, 2010.

[4] M. Van Dinther, F. Dochy, and M. Segers, "Factors affecting students' self-efficacy in higher education," Educational research review, vol. 6 , no. 2, pp. 95-108, 2011.

[5] V. Tinto, "Dropout from higher education: A theoretical synthesis of recent research," Review of Educational Research, vol. 45, no. 1, pp. 89-125, 1975.

[6] B. Rickinson and D. Rutherford, "Increasing undergraduate student retention rates," British Journal of Guidance \& Counselling, vol. 23, no. 2, pp. 161-172, 1995.

[7] P. Kinnunen and L. Malmi, "Why students drop out cs1 course?" in Proceedings of the Second International Workshop on Computing Education Research, ser. ICER '06. New York, NY: ACM, 2006, pp. 97-108, doi: 10.1145/1151588.1151604.

[8] J. Wray, J. Aspland, and D. Barrett, "Choosing to stay: Looking at retention from a different perspective," Studies in Higher Education, vol. 39, no. 9, pp. 1700-1714, 2014.

[9] V. Tinto, "Through the eyes of students," Journal of College Student Retention: Research, Theory \& Practice, vol. 19, no. 3, pp. 254-269, 2017.

[10] V. Hämäläinen and V. Isomöttönen, "What did CS students recognize as study difficulties?" in 2019 IEEE Frontiers in Education Conference (FIE). IEEE, Oct. 2019, pp. 1-9.

[11] A. Bandura, Social foundations of thought and action: A social cognitive theory. Englewood Cliffs, NJ: Prentice Hall, 1986.

[12] N. K. Turner, "Development of self-belief for employability in higher education: Ability, efficacy and control in context," Teaching in Higher Education, vol. 19, no. 6, pp. 592-602, 2014.

[13] K. Luyckx, S. J. Schwartz, M. D. Berzonsky, B. Soenens, M. Vansteenkiste, I. Smits, and L. Goossens, "Capturing ruminative exploration: Extending the four-dimensional model of identity formation in late adolescence," Journal of Research in Personality, vol. 42, no. 1, pp. 58-82, 2008.

[14] J. E. Marcia, "Development and validation of ego-identity status," Journal of Personality and Social Psychology, vol. 3, no. 5, p. 551, 1966.

[15] E. H. Erikson, Identity: Youth and Crisis. WW Norton \& Company, 1968.
[16] K. Luyckx, L. Goossens, and B. Soenens, "A developmental contextual perspective on identity construction in emerging adulthood: Change dynamics in commitment formation and commitment evaluation," Developmental psychology, vol. 42, no. 2, p. 366, 2006. [Online]. Available: https://doi.org/10.1037/0012-1649.42.2.366

[17] R. Mannerström, A. Hautamäki, and S. Leikas, "Identity status among young adults: Validation of the dimensions of identity development scale (dids) in a finnish sample," Nordic Psychology, vol. 69, no. 3, pp. 195213, 2017.

[18] Ü. Morsünbül, "The effect of identity development, self-esteem, low self-control and gender on aggression in adolescence and emerging adulthood,' Eurasian Journal of Educational Research, no. 61, 2015.

[19] U. Morsunbul and F. Cok, "The adaptation of the dimensions of identity development scale into turkish," Dusunen Adam, vol. 27, no. 1, pp. 6-14, 2014.

[20] E. Topolewska and J. Cieciuch, "Empirical verification of the circumplex of identity formation modes and its potential to integrate different models of identity development in the erikson-marcia tradition," Self and Identity, vol. 16, no. 2, pp. 123-142, 2017.

[21] B. M. Capobianco, "Undergraduate women engineering their professional identities," Journal of Women and minorities in Science and Engineering, vol. 12, no. 2-3, p. 95-117, 2006.

[22] B. M. Capobianco, B. F. French, and H. A. Diefes-Dux, "Engineering identity development among pre-adolescent learners," Journal of Engineering Education, vol. 101, no. 4, pp. 698-716, 2012.

[23] M. Sherer, J. E. Maddux, B. Mercandante, S. Prentice-Dunn, B. Jacobs, and R. W. Rogers, "The self-efficacy scale: Construction and validation," Psychological reports, vol. 51, no. 2, pp. 663-671, 1982.

[24] A. Bandura, "Self-efficacy: Toward a unifying theory of behavioral change," Psychological Review, vol. 84, no. 2, pp. 191-215, 1977.

[25] M. Hlavac, stargazer: Well-Formatted Regression and Summary Statistics Tables, 2018, r package version 5.2.2. [Online]. Available: https://cran.r-project.org/web/packages/stargazer/index.html

[26] F. E. Harrell Jr and M. F. E. Harrell Jr, "Package 'hmisc'," CRAN2018, pp. 235-6, 2015.

[27] V. Tinto, "Through the eyes of students," Journal of College Student Retention: Research, Theory \& Practice, vol. 19, no. 3, pp. 254-269, 2017.

[28] L. Wheelahan, "The problem with CBT (and why constructivism makes things worse)," Journal of Education and Work, vol. 22, no. 3, pp. 227 242, 2009.

[29] V. Isomöttönen, M. Daniels, Å. Cajander, A. Pears, and R. McDermott, "Searching for global employability: Can students capitalize on enabling learning environments?" ACM Transactions on Computing Education - Special Issue on Global Software Engineering Education, vol. 19, no. 2, pp. 11:1-11:29, Jan. 2019. [Online]. Available: http://doi.acm.org/10.1145/3277568

[30] C.-M. Zhao and G. D. Kuh, "Adding value: Learning communities and student engagement," Research in higher education, vol. 45, no. 2, pp. $115-138,2004$ 